\title{
“KEBUMILTAR" (KELOMPOK IBU HAMIL PINTAR) SEBAGAI UPAYA PENURUNAN ANGKA KOMPLIKASI PERSALINAN IBU DI WILAYAH PESISIR KABUPATEN NAGAN RAYA
}

\author{
Teungku Nih Farisni ${ }^{1}$, Dian Fera ${ }^{2}$ \\ ${ }^{1,2}$ Fakultas Kesehatan Masyarakat, Universitas Teuku Umar \\ 1. teungkunihfarisni@utu.ac.id, ${ }^{2}$ dianfera@utu.ac.id
}

\begin{abstract}
ABSTRAK
Tingginya angka kematian ibu dan bayi di wilayah pesisir Kabupaten Nagan Raya menjadi perhatian khusus disektor kesehatan. Salah satu penyebabnya adalah pendidikan pada masa hamil (prenatal) yang minim, pendidikan prenatal sangat penting dalam rangka mempersiapkan pasangan untuk menjadi orang tua. Kurangnya pengetahuan ibu hamil tentang kehamilannya merupakan salah satu bentuk ketidakberdayaan yang dapat mendukung tingginya angka kematian ibu/perinatal. Kegiatan pengabdian ini dilakukan bertujuan untuk mengimplemantasikan program berbasis masyarakat yang memfasilitasi masyarakat untuk membentuk kelompok hamil pintar dan meningkatkan pengetahuan ibu hamil dan meningkatkan kepatuhan ibu hamil untuk melakukan Antenatal Care (ANC) di Wilayah Pesisir Kabupaten Nagan Raya. Metode Penelitian ini adalah one group pre post design dengan Training Of Trainer (TOT) kader berjumlah 10 kader yang diukur pengetahuan, sikap, dan self-efficasy sebelum dan sesudah TOT. Instrumen yang digunakan adalah instrumen baku yang terdapat pada pedoman kelas ibu hamil. Setelah kader mengikuti TOT, kemudian kader membentuk kelompok ibu hamil pintar berjumlah 2 kelompok (10 ibu hamil/kelompok). Analisis data menggunakan distribusi frekuensi dan uji Wilcoxon. Hasil kegiatan pengabdian ini adalah terdapat perbedaan yang signifikan dari pengetahuan, sikap, dan self-efficacy kelompok ibu hamil pintar (P-Value < 0,05). Melalui pembentukan kelompok ibu hamil pintar ini dapat diaplikasikan secara mandiri dan kontinue melalui kader kesehatan dengan pengawasan petugas kesehatan, sehingga bisa menurunkan angka kematian ibu dan angka kematian bayi.
\end{abstract}

Kata Kunci: Ibu-hamil, Pintar, Kader, ANC

\section{ABSTRACT}

The high maternal and infant mortality rates in the coastal areas of Nagan Raya Regency are of particular concern in the health sector. One reason is that education in the prenatal period is minimal, prenatal education is very important in order to prepare couples to become parents. Lack of knowledge of pregnant women about pregnancy is one form of helplessness that can support the high maternal / perinatal mortality rate. This service activity was carried out aimed at implementing community-based programs that facilitate the community to form smart pregnancy groups and increase the knowledge of pregnant women and increase the adherence of pregnant women to carry out Antenatal Care (ANC) in the Coastal Area of Nagan Raya Regency. The method of this research is one group pre post design with training of trainers (TOT) cadres totaling 10 cadres who measured knowledge, attitudes, and self-efficacy before and after TOT. The instruments used were standard instruments contained in class guidelines for pregnant women. After the cadres joined TOT, then the cadres formed 2 groups of smart pregnant women (10 pregnant women / groups). Data analysis using frequency distribution and Wilcoxon test. The result of this service activity is that there is a significant difference from the knowledge, attitudes, and self-efficacy of the group of smart pregnant women $(P$-Value $<0.05)$. Through the establishment of this group of 
smart pregnant women, it can be applied independently and continuously through health cadres with the supervision of health workers, so as to reduce maternal.

Keywords: Mother-pregnant, Smart, Cadre, ANC

PENDAHULUAN

Angka Kematian Ibu berdasarkan Survey Demografi Kesehatan Indonesia (SDKI) tahun 2012 mengalami peningkatan (dari 228 per 100.000 kelahiran hidup menjadi 359 per100.000 kelahiran hidup). Penyebab langsung kematian ibu adalah perdarahan $60-70 \%$, eklamsi $10-20 \%$, dan infeksi 10-20\%.Salah satu penyebab perdarahan adalah atonia uteri sebagai dampak dari kelemahan kontraksi uterus atau kelemahan ibu, sedangkan sepsis adalah dampak dari persalinan lama atau kasep. Salah satu intervensi kesehatan yang efektif untuk mencegah kesakitan dan kematian ibu adalah pelayananprenatal (SDKI, 2012).

Upaya untuk menurunkan AKI dapat dilakukan dengan upaya preventif dan promotif dengan melibatkan semua unsur dalam masyarakat dan dilakukan secara terus menerus dan konsisten. Strategi yang dapat dilakukan adalah dengan menyelenggarakan kelas prenatal (kelas ibu hamil). Kelas prenatal adalah suatu kelas yang ditujukan untuk meningkatkan pemahaman perempuan, pasangan dan keluarga tentang persiapan kehamilan, kehamilan, persalinan dan nifas serta perawatan bayi baru lahir (Saifuddin, 2012).

Selama kehamilan upaya pemeliharaan dan peningkatan kesehatan ibu memerlukan perhatian ekstra sehingga kondisi kesehatan ibu tetap terjaga atau diusahakan minimal sama dengan kondisi kesehatan sebelum hamil. Hal-hal yang memerlukan perhatian itu antara lain nutrisi, persiapan laktasi, pemeriksaan kehamilan yang teratur, peningkatan kebersihan diri dan lingkungan, kehidupan seksual, istirahat dan tidur, menghentikan kebiasaan yang merugikan kesehatan dan berpengaruh terhadap janin (seperti merokok), melaksanakan pergerakan dan senam hamil. Upaya-upaya itu ada yang ditujukan untuk menjaga kesehatan ibu dan fetus, disamping itu dimaksudkan juga sebagai persiapan menghadapi persalinan dan nifas seperti persiapan laktasi dan senam hamil (Anggeriani, 2013).

Beberapa penelitian sebelumnya adalah penelitian yang dilakukan Romlah (2009) menunjukkan bahwa pada kelompok ibu-ibu yang mengikuti kelas ibu hamil memiliki peluang 16.9 kali untuk berperilaku positif dibandingkan dengan kelompok-kelompok ibu yang tidak mengikuti kelas ibu hamil (Usman, 2009). Kemudian pada penelitian lain yang dilakukan oleh Widayati (2011) mengenai faktor yang berhubungan dengan kunjungan kelas ibu hamil menunjukkan bahwa pengetahuan dan sikap ibu berhubungan erat dengan perilaku ibu dalam malakukan kunjungan ke kelas ibu hamil. 
Berdasarkan survey pendahuluan ANC selain karena jauhnya tempat diperoleh tingginya angka kematian ibu di daerah pesisir Kabupaten Nagan Raya hal ini disebabkan oleh pendarahan dan eklampsia. Pendidikan pada masa hamil (prenatal) sangat penting dalam rangka mempersiapkan pasangan untuk menjadi orang tua. Kurangnya pengetahuan ibu hamil tentang kehamilannya merupakan salah satu bentuk ketidakberdayaan yang dapat mendukung tingginya angka kematian ibu/perinatal. Secara tradisional wanita belajar tentang perawatan kehamilan, persalinan, nifas, dan pengasuhan bayi dari orang tua mereka ataupun saudara mereka. Tentu saja, pengetahuan yang didapatkan dari melalui keluarga ini hanya berupa pengalaman individual yang tidak dapat dipertanggungjawabkan secara ilmiah. Hasil wawancara dengan bidan desa didapatkan data bahwa hampir 60\% ibu hamil tidak secara rutin melakukan Antenatal Care dengan alasan jauhnya tempat pelayanan kesehatan, tidak adanya kader kesehatan yang terlatih di desa untuk memantau kesehatan ibu hamil dan sebagian besar ibu melahirkan dirujuk ke RS dengan indikasi medis seperti ibu hamil dengan komplikasi persalinan, ibu hamil dengan anemia dan kesulitan dalam persalinan (distosia). Komplikasi kehamilan dan persalinan tersebut pada dasarnya dapat dideteksi lebih dini jika ibu rutin dan patuh melakukan ANC. Ketidakpatuhan untuk melakukan pelayanan kesehatan juga didukung oleh kurangnya pengetahuan ibu hamil akan pentingnya melakukan ANC sebagai upaya untuk deteksi dini kondisi kesehatan ibu hamil dan janinnya. Melihat potensi dan kondisi ibu hamil di Daerah Pesisir Kabupaten Nagan Raya perlu dikembangkan suatu program yang bertujuan untuk meningkatkan pengetahuan ibu hamil dan meningkatkan kepatuhan ibu hamil untuk melakukan ANC dengan pendekatan peer group melalui "KEBUMILTAR". Kegiatan ini bertujuan untuk mengimplemantasikan program berbasis masyarakat yang memfasilitasi masyarakat untuk membentuk kelompok hamil pintar dan meningkatkan pengetahuan ibu hamil dan meningkatkan kepatuhan ibu hamil untuk melakukan Antenatal Care (ANC) sebagai upaya penurunan angka komplikasi persalinan pada ibu hamil dengan melatih 10 orang kader kesehatan dan membentuk 2 kelompok ibu hamil di Wilayah Pesisir Kabupaten Nagan Raya.

\section{PERMASALAHAN MITRA}

Berdasarkan analisis situasi, diketahui bahwa di desa mitra yaitu gampong padang rubek dan gampong kuala baroe tidak berjalannya kelas ibu hamil. Sejalan dengan permasalahn tersebut Permasalahan yang dialami oleh mitra adalah sebagai berikut :

1. Kader kesehatan belum memiliki pengetahuan dan keterampilan yang 
baik tentang pelaksanaan kelas ibu hamil.

2. Minimnya pengetahuan ibu hamil dalam menjaga kehamilan yang sehat.

3. Ketidakpatuhan ibu hamil dalam melakukan ANC.

4. Ketidaksiapan ibu untuk menghadapi proses persalinan baik persiapan fisik maupun psikologis.

5. Kurangnya peran serta keluarga dalam mendampingi ibu selama masa kehamilannya.

Berdasarkan permasalahan mitra tersebut, maka dilaksanakanlah TOT pada kader kesehatan dan pembentukan kelompok ibu hamil pintar sebagai upaya penurunan angka komplikasi persalinan pada ibu hamil.

\section{METODE}

Metode yang digunakan dalam kegiatan ini adalah Training Of Trainer (TOT) kader kesehatan dengan melakukanpra tes dan pasca test. Materi untuk TOT disampaikan oleh 2 orang narasumber yang terdiri dari seorang tim ahli dan tim pengabdi yang berperan sebagai pemberdaya, penyuluh dan fasilitator.

Tahapan kegiatan pengabdian dapat diuraikan sebagai berikut :

1. Pembentukan fasilitator kelas ibu hamil (kader ibu hamil)

a. Pembentukan fasilitator atau kader kesehatan; melakukan seleksi kader kesehatan, dalam hal ini akan dipilih kader yang aktif dalam posyandu.

b. Mengadakan pelatihan kader ibu hamil.

c. Persiapan atau pengadaan peralatan pendukung yang dibutuhkan dalam pelatihan.

d. Melaksanakan pelatihan dengan metode pendekatan diskusi, simulasi/ demonstrasi, dan roleplay.

2. Membentuk KEBUMILTAR "Kelompok Ibu Hamil Pintar"

a. Identifikasi ibu hamil di daerah pesisir Kabupaten Nagan Raya.

b. Penyusunan struktur organisasi kelompok ibu hamil.

c. Sosialisasi tujuan pembentukan kelompok ibu hamil.

d. Penyusunan rencana kegiatan kelompok ibu hamil.

e. Pengadaan peralatan yang dibutuhkan

f. Publikasi dan sosialisasi program kepada masyarakat.

g. Soft opening kelompok ibu hamil.

Teknik Pengumpulan dan analisis data

Evaluasi kegiatan ini dilakukan dengan melihat pengetahuan, sikap, dan selfefficasy sebelum dan sesudah TOT pada kader kesehatan. Tingkat pengetahuan dan sikap digolongkan berdasarkan skor pengetahuan dan sikap yang diukur menggunakan instrumen kuesioner yang baku diambil dari buku pedoman kelas ibu hamil. Tingkat pengetahuan dan sikap dikategorikan menjadi 2 yaitu jika menjawab 
benar $\geq 60 \%$ dinyatakan pengetahuan, sikap, daan self-efficacy baik. Apabila kader menjawab benar $\leq 60 \%$ dinyatakan pengetahuan, sikap, daan self-efficacy kurang baik dalam menjalankan edukasi kepada ibu hamil. Analisis menggunakan analisis univariat dan bivariat. Analisis bivariat menggunakan uji statistik wilcoxon untuk mengetahui perbedaan rata-rata pengetahuan, sikap, dan self-efficacy sebelum dan sesudah TOT.

Alur kegiatan Pengahadian

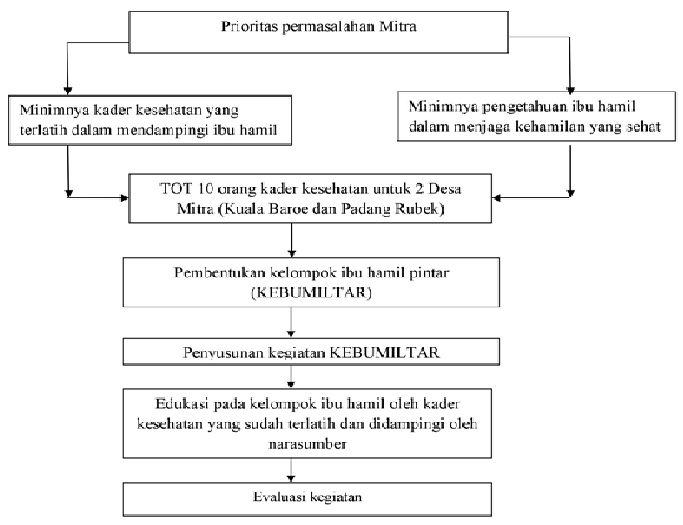

HASIL DAN LUARAN YANG DICAPAI

Kegiatan TOT dilakukan di balai desa Kuala baroe dengan jumlah peserta 10 orang kader kesehatan. Seluruh peserta TOT berjenis kelamin perempuan yang sebagian besar adalah ibu rumah tangga dengan kisaran umur dari 20 - 35 tahun. Kegiatan ToT ini bertujuan untuk mengetahui gambaran tingkat pengetahuan, sikap dan self efficacy kader kesehatan dalam mendampingi edukasi pada ibu hamil. Dengan ToT ini dapat meningkatkan pengetahuan kader kesehatan sebagai ujung tombak untuk menurunkan angka komplikasi persalinan pada ibu hamil melalui pendampingan ibu hamil untuk menjaga kehamilannya dengan bantuan bidan desa.

Tabel 1. menunjukkan karakteristik kader yang dilibatkan dalam kegiatan TOT. Sebagian besar kader bekerja (70\%). Sebagian besar telah lama menjadi kader 1-5 tahun (60\%). Semua kader belum pernah mengikuti pelatihan tentang kesehatan ibu hamil dan tidak memiliki pengalaman dalam pendampingan ibu hamil.

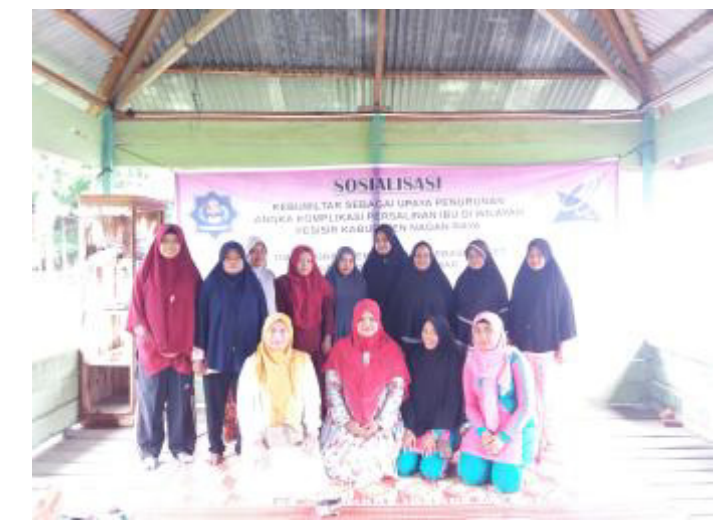

Gambar 1. Kegiatan Sosialisasi Kebumiltar

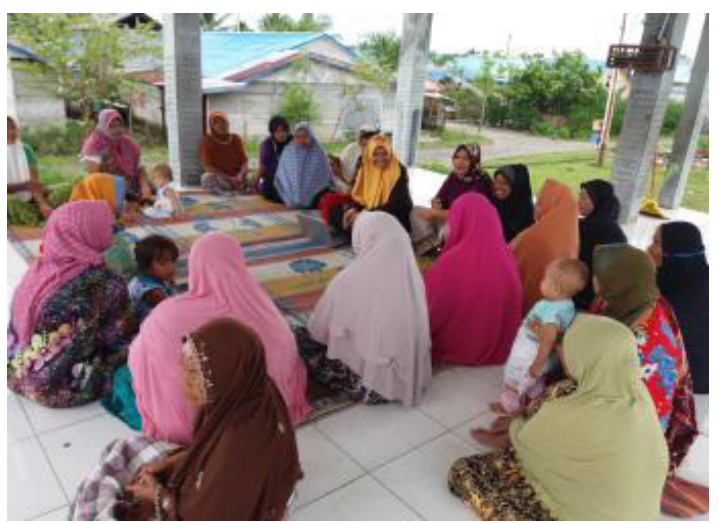

Gambar 2. Diskusi terarah dengan Kader Kesehatan dan ibu hamil 
Tabel 1.Karakteristik Kader Kesehatan Training of Trainer (TOT) di Gampong Kuala Baroe dan Gampong Padang Rubek

\begin{tabular}{|c|l|c|c|}
\hline No & \multicolumn{1}{|c|}{ Variabel } & $\mathrm{n}$ & Persentase (\%) \\
\hline 1 & Usia & & \\
& 20-30 tahun & 3 & 30 \\
& $31-40$ tahun & 5 & 50 \\
& $41-50$ tahun & 2 & 20 \\
\hline 2 & Status & 2 & \\
& BelumKawin & 8 & 20 \\
& Kawin & & 80 \\
\hline 3 & Pekerjaan & 3 & 30 \\
& Tidakbekerja & 7 & 70 \\
\hline 4 & Bekerja (petani dan pedagang) & & \\
& Pendidikan & 6 & 40 \\
& Rendah & 6 & 60 \\
\hline 5 & Tinggi & 6 & 60 \\
& Lama Menjadi Kader & 4 & 40 \\
\hline
\end{tabular}

Sumber: Data primer diolah, gampong Padang Rubek dan gampong Kuala Baroe

Tabel 2.Hasil Distribusi Frekuensi Pengetahuan Kader Kesehatan sebelum dan sesudah Training Of Trainer (TOT) di Gampong Kuala Baroe dan Gampong Padang Rubek

\begin{tabular}{|c|c|c|c|c|c|c|}
\hline \multirow{2}{*}{ Variabel } & \multicolumn{2}{|c|}{ Sebelum } & \multicolumn{2}{c|}{ Sesudah } & \multicolumn{2}{c|}{ Total } \\
\cline { 2 - 7 } & $\mathrm{n}$ & $\%$ & $\mathrm{n}$ & $\%$ & $\mathrm{n}$ & $\%$ \\
\hline Pengetahuan & & & & & & \\
$\quad$ a. Kurangbaik & 6 & 60 & 2 & 20 & 8 & 40 \\
b. Baik & 4 & 40 & 8 & 80 & 12 & 60 \\
\hline Sikap & & & & & & \\
a. KurangBaik & 7 & 70 & 4 & 40 & 11 & 55 \\
b. Baik & 3 & 30 & 6 & 70 & 9 & 45 \\
\hline Self-Efficacy & & & & & & \\
a. KurangBaik & 8 & 20 & 6 & 60 & 14 & 70 \\
b. Baik & 2 & 80 & 4 & 40 & 6 & 30 \\
\hline
\end{tabular}

Sumber: Data primer diolah, gampong Padang Rubek dan gampong Kuala Baroe

Tabel 3.Hasil Uji Perbedaan Rata-rata Pengetahuan, Sikap, Self-Efficacy Kader Kesehatan sebelum dan sesudah Training Of Trainer (TOT) di Gampong Kuala Baroe dan Gampong

Padang Rubek

\begin{tabular}{|l|l|l|l|l|}
\hline \multicolumn{1}{|c|}{ Variabel } & Sebelum M(SD) & Sesudah M(SD) & $\mathrm{Z}$ & $\mathrm{P}$ \\
\hline Pengetahuan & $6,6(0,4)$ & $8,88(0,12)$ & $-2,56$ & 0,001 \\
\hline Sikap & $5,46(0,28)$ & $7,56(0,07)$ & $-2,32$ & 0,012 \\
\hline Self-Efficacy & $4,37(0,5)$ & $6,9(0,24)$ & $-3,15$ & 0,004 \\
\hline
\end{tabular}

Sumber: Data primer diolah, gampong Padang Rubekdangampong Kuala Baroe 
Tabel 2. Menunjukkan bahwa hasil distribusi frekuensi pengetahuan, sikap dan self-efficacy kader sebelum dan sesudah mengalami peningkatan.

Tabel 3. Menggambarkan rata-rata pengetahuan, sikap, dan self-efficacy pada kader sebelum dan sesudah ToT terdapat perbedaan bermakna pada rata-rata pengetahuan, sikap dan self-efficacy pada kader sebelum dan sesudah ToT di Gampong Padang Rubek dan gampong Kuala Baroe.

Setelah dilaksanakannya ToT bagi kader kesehatan, kemudian dibentuk 2 kelompok ibu hamil pintar yang terdiri dari 2 kelompok sebanyak 20 orang ibu hamil. Kelompok tersebut menyusun rencana kegiatan ibu hamil yang didampingi oleh kader yang sudah terlatih dan narasumber. Dalam kelompok tersebut dibuatlah diskusi kelompok terarah yang bertujuan untuk mengetahui gambaran pengetahuan ibu hamil untuk kehamilan yang sehat. Dengan diskusi terarah, dapat mengetahui pesepsi, opini dan sikap ibu hamil dalam menjaga kehamilannya. Hasil diskusi diketahui bahwa masih banyak ibu-ibu hamil yang tidak mengetahui tanda dan gejala komplikasi persalinan, masih banyak ibu yang melakukan pantangan makanan selama kehamilan, belum pernah melakukan senam hamil. Kelas ibu hamil ini terus berjalan dan bertujuan untuk menurunkan angka komplikasi persalinan, kelas ibu tersebut didampingi oleh kader kesehatan yang sudah mendapat ToT.

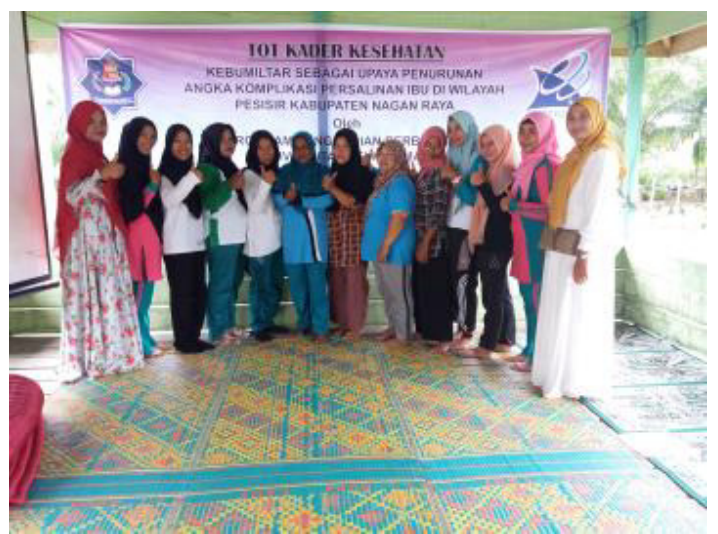

Gambar 3. ToT Kader Kesehatan

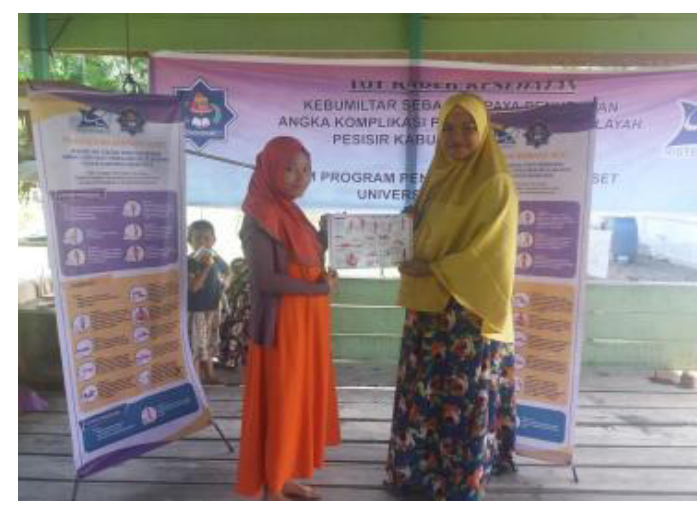

Gambar 4. Penyerahan alat yang dibutuhkan oleh ibu hamil

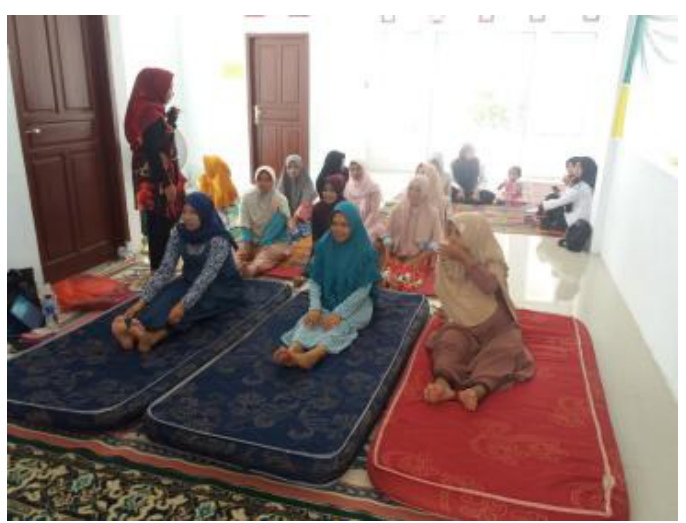

Gambar 5. Senam Ibu Hamil 


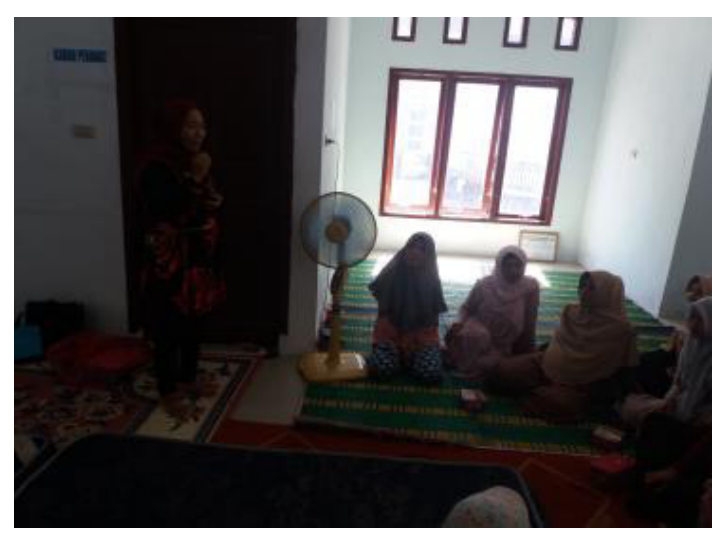

Gambar 6. Soft Opening pada Kelompok Ibu Hamil

\section{KESIMPULAN}

Pelaksanaan ToT dan pembentukan kelompok ibu hamil pintar di gampong Kuala Baroe dan Gampong Padang Rubek dapat meningkatkan pengetahuan, sikap dan self Efficacy pada kader dan ibu hamil sehingga dapat menurunkan angka komplikasi persalinan di wilayah pesisir Kabupaten Nagan Raya.

\section{DAFTAR PUSTAKA}

Anggeriani (2013). Senam Hamil. Posted on January 16, 2013

Booth,T. 2010. Tanya Jawab Seputar Kehamilan, (terjemahan). Jakarta: PT Bhuana Ilmu Populer

Chandra, E. 2011. Baby Guide. Bali: Maxmadia.

Depkes RI, WHO. 2013. Asuhan Kebidanan Post Partum. Jakarta, Pusdiknakes RI.

Hardiyanti Chandra Dewi (2013). Proses Persalinan Pada Ibu Hamil " $H$ " Umur 26 Tahun.

Primigravida Yang Rutin Mengikuti Senam Hamil Selama Kehamilan Trimester Ketiga.

Diakses pada tanggal 29 Mei 2013

Kushartanti,Bm.Wara.(2010).Senam Hamil.

Cetakan 1.Yogyakarta:Lintang Pustaka

Manuaba, Ida Bagus Gde. 2008. Ilmu
Kebidanan Penyakit Kandungan \& Keluarga Berencana untuk Pendidikan Bidan. Jakarta: EGC.

Mander,R.2013. Nyeri Persalinan (terjemahan). Jakarta: EGC

Saifudin, AB. 2012. Buku Acuan Nasional Pelayanan Kesehatan Maternal dan Neonatal. Jakarta: Yayasan Bina Pustaka Sarwono Prawirohardjo.

Survey Demografi Kesehatan Indonesia, Tahun 2012.

Usman, Yerniah Iswanti (2009). Hubungan Senam Hamil dengan Power Ibu pada Proses Persalinan Kala II di RS Panti Wilasa Citarum Semarang periode Triwulan I Tahun 2009. Semarang: Diponegoro University undergraduate thesis; 2009.

Varney, Helen. (2009). Buku Ajar Asuhan Kebidanan. Jakarta: EGC.

Wiknjosastro, H. 2012. Ilmu Kebidanan. Jakarta: Yayasan Bina Pustaka Sarwono Prawirohardjo. 